\section{Mediating Age-related Cognitive Decline through Lifestyle Activities: A Brief Review of the Effects of Physical Exercise and Sports-playing on Older Adult Cognition}

\section{Abstract}

Normal aging is associated with variable declines in perception and cognition, which may be mediated through active engagement in certain lifestyle activities. The aim of this review was to discuss the relationship between cognitive functioning in older adulthood and participation in various types of physical exercise and sportsplaying activities. Most studies have focused on the beneficial effects of relatively nonspecific forms of aerobic physical activity, although some emerging evidence has suggested that more specific forms of sports-playing activities may confer greater cognitive benefit in specific areas of cognitive functioning. The evidence reviewed suggests the potential for simple lifestyle-related behaviors to mediate the cognitive decline often found in older adults, and to enhance the aging brain's cognitive reserve. However, more work is needed in order to ascertain the variable outcomes of exercise type, duration, and frequency, and the cognitive effects of various sports activities.

Keywords: Cognitive functioning; Brain health; Working memory; Eye diseases; Diabetes mellitus

\section{Inga Sogaard and Rui Ni* \\ Department of Psychology, Wichita State University, Wichita, KS, USA}

*Corresponding author: Rui $\mathrm{Ni}$

E rui.ni@wichita.edu

Associate Professor, Department of Psychology, Wichita State University, Wichita, KS, USA.

Tel: (316) 978-3886

Fax: (316) 978-3086

Citation: Sogaard I, Ni R (2018) Mediating Age-related Cognitive Decline through Lifestyle Activities: A Brief Review of the Effects of Physical Exercise and Sports-playing on Older Adult Cognition. Acta Psychopathol Vol.4 No.5:22

Received: August 27, 2018; Accepted: September 10, 2018; Published: September 29, 2018

\section{Introduction}

As we age, we experience changes in our ability to carry out complex, yet quotidian tasks, such as driving, which requires the possession of sufficient perceptual and cognitive skills. Contributing factors likely involve normative cognitive declines that are outward manifestations of the inherent neurophysiological changes that take place within the aging brain. In light of the globally increasing proportion of older adults, the question of how to offset and even reverse structural and functional decline is steadily gaining in importance. Understandably, retaining cognitive health into older adulthood is of great concern to most older adults [1]. Both scholarly and commercial interest has been vested in identifying ways in which cognition can be stimulated in a way that can promise transfer to real-world tasks and activities. Proposed activities have included engaging more frequently in everyday activities, such as completing crossword puzzles, playing card games, and learning a new language, or more formal training procedures. Many studies have examined the impact of cognitive training on older adults, with some improvements found in areas of attention and memory [2-5]. However, specificity of learning is a common feature of cognitive training paradigms that fail to show a transfer to real-world outcomes [6].

For the purpose of attaining more general learning effects, recent research has focused on modifiable lifestyle factors and other real-world experiences. Epidemiological studies have suggested that older adults who remain active as they age, and participate in stimulating mental, physical, and social activities may delay or even avoid cognitive decline $[7,8]$. Learning that occurs under such conditions typically features more complex learning paradigms compared to most laboratory-based manipulations, thus avoiding the exceptional specificity that is a feature of many cognitive training procedures. Activities that have been found to lead to more generalized cognitive effects have included video game playing [9], musical training [10], and physical activity training [11]. Real-world activities are inherently complex, and access multiple cognitive systems simultaneously during information processing and task execution. Here we have focused this review on evidence that indicates a relationship between physical exercise and cognitive functioning and brain health. Specifically, we review the existing evidence that different types 
of exercise and sports activities may have differential effects on cognitive health.

\section{Age-related declines in perceptual and cognitive functioning}

There is substantial evidence that many cognitive abilities show decline as a function of age, although the distinction between normal and pathological cognitive aging is far from a straightforward process. Despite the considerable prevalence of mild cognitive impairment and dementia in older age, subjective cognitive complaints and subtle performance changes across a range of cognitive domains are much more common. Even in the absence of early clinical signs of dementia or other pathological changes, a gamut of cognitive abilities tends to show a gradual decline with age. A diminished processing speed has been wellestablished and associated with the decline observed with many other cognitive abilities [12], including memory [13]. Greater age-related memory declines are typically observed in episodic memory (i.e., the ability to remember specific events from the past), whereas the retrieval of sematic memories (i.e., more general world knowledge) is typically observed in very advanced age [14]. The ability to both encode and retrieve newly acquired information also tends to show a decline with age [15]. A wide range of changes have been observed in the set of cognitive processes referred to as executive functioning, including noticeable declines in response inhibition [16], task switching [17], and decision-making [18]. Moreover, aging may affect attentional abilities [19], divided attention [20], visual working memory [21], verbal and spatial working memory [22], and dual task processing [23]. However, some cognitive abilities, such as procedural memory [24] and knowledge-based abilities (e.g. vocabulary) [25]. Do appear to go relatively unscathed well into the ninth decade of life.

Age-related cognitive changes have been linked to various underlying neurocognitive changes found in healthy older adults without sign of dementia. Studies on normal brain aging have found atrophy of the frontal and temporal lobes [26,27], changes in white matter [28], and a reduction in neuronal connectivity [29]. Furthermore, there is evidence of pathological depositions, volumetric loss, and biomarkers characteristic of dementia within the brains of older adults with subjective cognitive impairment, but who do not fit the objective criteria for a dementia diagnosis [30-32]. The structural changes found in healthy older adults are significantly less than the volumetric measurements found in patients with Alzheimer's disease or $\mathrm{MCl}$, particularly within the temporal lobes [33].

While neurodegenerative dementia forms such as Alzheimer's disease are characterized by considerable functional decline (e.g., in activities of daily living), subtle age-related performance decrements in cognitive domains are not thought to incur any significant functional limitations in the ability to perform most everyday tasks. However, for tasks that requires a complex integration of information and the enlistment of multiple cognitive domains, such as driving, subtle age-related changes may translate into behavioral decrements and hazardous situations [34]. Decrements in driving ability have been linked to domains including visual attention (e.g., dividing attention between multiple input channels), visual processing speed, visual perception, memory, and executive functions (i.e., the ability to flexibly adapt and respond to situational changes) $[35,36]$. For example, older adults may experience decrements in their ability to attend to multiple lanes of traffic simultaneously or accurately judge their distance from a curb. Given that older drivers are at much higher risk for motor vehicle crashes [37], a focus of research should be on determining ways to improve these driving-related cognitive and perceptual functions before unsafe driving behaviors are introduced. Driving-related perceptual and cognitive functions are a prime target for remedial activities, as driving is an everyday task that is important for maintaining independence in older adulthood.

In concert with cognitive changes across the lifespan, many visuoperceptual functions likewise suffer from age-related declines. Particularly in old age, a substantial link between sensory functioning and fluid cognitive abilities (e.g., processing speed) has been established [38]. In terms of functional risk, diminished visual functioning in normally aging adults has been identified as a contributor to an increased incidence of falls [39] and increased risk of motor vehicle accidents [36] as well as a conglomeration of difficulties in performing everyday tasks. Deteriorations in visual acuity [40], contrast sensitivity [41], motion perception [42], orientation discrimination [43] and visual processing speed [36] have been documented in normally aging individuals. Some changes in visual capacities may be attributed to optical changes, while others may be attributed to neurophysiological changes in the visual pathways within the brain. Furthermore, the risk of several progressive and irreversible eye diseases increases with age. Common causes of visual impairment include cataracts, glaucoma, diabetic retinopathy, and age-related macular degeneration [44]. While any of these eye diseases may cause permanent structural changes, they are not able to fully account for age-related declines in perceptual abilities.

\section{Effects of physical training and enhanced fitness on older adult cognition}

Physical exercise is beneficial for older adults in terms of reducing the risk of a plethora of health conditions, including heart disease [45], diabetes mellitus [46], obesity [47], and osteoporosis and arthritis [48], all of which are diseases that increase in prevalence in older adulthood [49-52]. More generally, physical exercise is effective in increasing cardiovascular fitness, muscle strength, bone mineral density, alleviating depression and anxiety, and improving self-esteem in older adults [53]. In fact, evidence has suggested that higher physical activity levels lead to a longer total life expectancy [54]. Physical fitness has been associated with certain biological mechanisms that underlie the beneficial effects on physical and psychological health. Moreover, potential benefits to the brain may be conferred by biological mechanisms that support reduced inflammation, increased growth factor expressions, optimized neuroendocrine responses to stressors, and neuroplasticity [55]. 
Regular physical exercise has also been associated with better cognitive functioning and even a delayed onset of dementia types $[56,57]$. Higher levels of cognitive functioning have been found in both cognitively normal and demented older adults engaged in regular exercise $[11,57,58]$. The past several decades have seen a number of studies that have examined the effects of both single bouts of acute exercise and longer term (e.g. 3-12-month) interventions in younger and older adults. In a review of the literature, cognitive improvements in areas including simple reaction time, working memory, and even higher-order thinking processes, including creativity, were seen following acute bouts of short-duration exercise [59]. Hillman, Shook, and Jerome [60] examined the effects of 30-minutes of acute cardiovascular exercise on college-aged students by measuring performance on the Eriksen flanker task (interference control) and event related brain potentials. The authors found that exercise increased the amplitude of the P3 potential (thought to be an indicator of the allocation of attentional and working memory resources), suggesting that even short exercises sessions may induce neuroelectric changes that support executive control [60]. Acute exercise exposure of light to moderate intensity aerobic activity has demonstrated beneficial effects on older adult cognition on measures of reaction time [61], tests of working memory [62], and logical memory and Mini Mental State Examination (MMSE) scores [63]. However, studies that have sought to determine the effects of acute exercise have largely featured younger adult samples, leaving much still to be examined among adults 60 years and older. Thus, a priority of this line of research should be to evaluate the long-term impact that relatively short periods of exercise may have in sedentary older adults.

The protective effects of physical activity on cognition has been a research topic for decades throughout a number of crosssectional studies $[64,65]$. Several longitudinal studies have shown a diminished rate of cognitive decline in physically active older adults during variable follow-up periods. In a six-year longitudinal study of 349 community-living older adults, cardiorespiratory fitness levels were strongly predictive of performance on measures of global cognitive functioning and attention/executive function [66]. Aichberger and colleagues [67] measured the association between any type of regular physical activity and cognitive decline in a 2.5-year follow-up of an international sample of 17,333 individuals over the age of 50 from 11 European countries [67]. The authors found less evidence of cognitive decline in those who regularly engaged in any type of physical activity, particularly if those activities occurred more than once per week. Moreover, higher physical activity levels in older adults has been linked to a reduced risk of physical disability and mobility limitations [68]. Mobility limitations have in turn been implicated as a longitudinally predictive risk factor for cognitive impairment [69].

Intervention studies that have featured longer-term involvement in various forms of physical exercise have typically targeted older adult populations. The beneficial effects of physical exercise on cognitive functioning has been demonstrated throughout a number of intervention studies featuring healthy older adult participants, using aerobic activity and resistance exercises, both separately and in combination. Intervention studies have, in turn, lent the greatest support to the idea that physical exercise has an enhancing effect on older adult cognition. One 12-month program of 3-hour per week supervised endurance training of healthy older adults produced a stable cognitive status (as measured by follow-up MMSE scores) relative to a control group that received only lifestyle education [70].

Exercise participation has been implemented in a variety of physical intervention forms. Most intervention studies examining the effects of physical activity on cognition through large-scale randomized controlled trials have targeted relatively nonspecific forms of aerobic exercise [71]. Albeit fewer in number, combined aerobic and resistance training programs and other multicomponent programs seem to show better cognitive outcomes [72], predominantly in areas of attention and executive functioning [73].

Meta-analytic reviews of randomized design studies have established the robust and reliable benefit of fitness training interventions on the cognition of older adults [11]. Colcombe and Kramer [11] reported differential performance improvements in specific areas of cognitive functioning, with the greatest improvement in executive processes, followed by visuospatial functions. The authors found that combined strength and aerobic training programs produced the greatest degree of improvement when compared to aerobic training only. Furthermore, there does not appear to be a substantial difference in outcome between training programs of a longer duration ( $6+$ months) and those of shorter durations (1-3 months). However, there is still no clear dose-response relationship between the level and duration of the physical activity and the expected cognitive benefits. Additionally, the large body of literature in this area has engendered a great deal of heterogeneity in methods related to data collection, analysis, and neurocognitive assessment. In fact, the quality, lack of consistent use of clinically validated assessments, and statistical reports of many studies in this area have been questioned (see Smith et al., [71] for a discussion).

Most exercise intervention studies have featured healthy community-dwelling older adults. More studies conducted with physically frail older adults, or older adults with various cognitive impairments are needed in order to be able to generalize the cognitive benefits of physical activity to populations of older adults with preexisting cognitive or physical limitations. One study showed that physically frail older adults improved their cognitive performance in areas of executive functioning, processing speed, and working memory following three months of physical training [74]. The same study also found an improved physical capacity, quality of life, and satisfaction with physical capacity, health, and social relationships among participants. A 24-week, home-based physical activity program was able to prevent further cognitive decline in a group of older adults who had already presented with subjective memory impairments over an 18-month period [75]. A meta-analysis of physical exercise interventions in older adults with pre-existing cognitive impairments and dementia found support for the effectiveness of aerobic, resistance, and 
multi-component training programs on improved cognitive outcomes [58]. However, the authors note that this particular body of evidence is lacking in terms of adequate sample sizes, the quality of study design, experimental controls, and a need for long-term follow-up assessments.

\section{Neurophysiological benefits of aerobic activity}

The neurophysiological approach to the link between fitness and enhanced cognition has identified an increase in cerebral blood flow as an important mediating factor. Hypertension, diabetes mellitus, and other adverse cardiovascular outcomes and risk factors have negative implications for late life cognition [76]. For example, higher levels of neurofibrillary tangles and senile plaques (brain pathologies that are characteristic of Alzheimer's disease) have been observed in hypertensive individuals [77], and aerobic activity is often prescribed as a behavioral intervention for developing cardiovascular disease [78]. Vascular disease is second only to advanced age as the most significant risk factor for dementia. While senescence is not a factor amenable to change, the risk factors for vascular disease have the potential to become modified through lifestyle intervention [79]. Furthermore, exercise interventions may also reduce brain inflammation and improve the immune systems of older adults, thereby reducing risks associated with cognitive decline [80].

Exercise may mediate cognitive functioning and the benefits to overall brain health through several neurophysiological mechanisms. A growing body of research on non-human animals has implicated the cellular and molecular mechanisms which may account for the cognitive effects of physical exercise. Animal studies suggest that exercise-induced brain plasticity may be specifically related to increased neurotrophins, which stimulate neurogenesis, and increased vascular perfusion [81]. Voluntary exercise has been demonstrated as a behavioral mediator of axonal regeneration in the sensory neurons of animals following axonal injury [82]. These findings suggest that physical activity may embody a potential for activity-dependent plasticity and neuronal regeneration.

Enhanced spatial learning has been observed in rodents engaged in voluntary aerobic exercise (e.g., wheel running) [83,84], suspected to be caused by increased neurotrophin levels [85]. Furthermore, running has been found to produce a nearly threefold increase in neurogenesis in active aged mice compared to sedentary controls and recover age-related decline to $50 \%$ of that of young mice [85]. Running has also been shown to enhance hippocampal neurogenesis, synaptic plasticity and long-term potentiation in mice [84]. Hippocampal neurogenesis slows down considerably with age in rats [86] and regionally specific neuronal loss has been measured in the hippocampal areas of humans [87]. In addition to neurogenesis, voluntary aerobic fitness has been shown to increase levels of brainderived neurotrophic factor (BDNF) within hippocampal areas, which facilitates the maintenance and regeneration of nerve cells [81]. Therefore, increased availability of BDNF in learning and memory-dominant brain areas may prime cells for enhanced encoding of environmental information and promote learning in the aged brain. Additionally, evidence of synaptogenesis has also been reported as a molecular response to exercise [88]. The effects of aerobic exercise have been less studied in the human brain. Research on human populations has shown that aerobic fitness is positively correlated with increased grey and white matter volume [89] and sparing of the anterior white matter tracts which are most compromised by age-related decline [90]. Furthermore, human studies have revealed the plasticityinduced responsiveness of the hippocampus to physical activity [91]. Mechanisms of structural hippocampal change have been attributed to both angiogenesis (proliferation and new growth of blood vessels) [92] and neurogenesis (generation of new functional neurons from adult neural stem cells) [84].

\section{Differential effects of various physical and sports-playing activities on cognitive performance}

Research has increasingly supported the beneficial effects of (at least) moderately intense physical activities (e.g., running, tennis, aerobics, etc.) on the risk of all-cause mortality, type-2 diabetes, hypertension, stroke, colon cancer, breast cancer, depressive symptoms, and dementia [56,93]. The effects of lower intensity exercise (e.g. light walking, stretching, etc.) have been associated with more negligible health and cognitive benefits [94]. Specific types of sports-playing activities may also have varying effects on cognitive performance in older adults, given that different types of physical activities and sports involve distinct cognitive and physical demands. In particular, accumulating evidence seems to favor "open-skill sports" rather than "closed-skill sports" in terms of domain-specific cognitive performance. Open-skill sports (e.g. badminton, table tennis, etc.) require constant adaptation to dynamic environments, governed in part by the opposing player's behaviors (e.g., the varying speed of a ball). In contrast, closed-skill activities (e.g. walking, swimming, etc.) are often selfpaced, predictable, and carried out independently from the input of other players (e.g., a golfer attempting to replicate a swing). As such, meta-analytic reviews have supported better cognitive performance in areas of processing speed and attentional processes in "open-skill" sports-playing athletes [95].

Thus, the associated skills of open-skill sports are constrained by the external environment, and involve different perceptual, cognitive, and motor processes. Therefore, it is important to identify the more task-relevant benefits of sports playing rather than just the overall benefits of general aerobic training. Studies have shown that skilled players of open-skill sports have demonstrated superior performance on cognitive tasks measuring processing speed, visual attention, visual working memory, inhibitory control, and decision making relative to athletes of closed-skill sports [95,96]. Many open-skill sports are highly perceptual in nature and involve considerable cognitive load, as they require attending to relevant sensory information, adjusting attention, planning, cognitive flexibility, and immediate decision making in the presence of incomplete information [97]. For example, the perceptual nature of open-skill sports has been demonstrated in the superior accuracy of skilled racket sports players in detecting and utilizing subtle cues from an 
opponent's postural orientation before the interceptive actions are performed [98]. Moreover, skilled players of various racket sports are able to provide accurate predictions of potential shots before they have been made by the opponent $[99,100]$. These findings suggest that extended engagement in various types of open-skill racket sports may foster certain perceptual-cognitive skills that enable players to use advanced visual cues to process information more efficiently, and to rapidly and flexibly adapt to situational changes.

The differential cognitive effects of exercise mode have been supported in older adults within some cognitive domains. Older adults engaged in open-skills sports-playing demonstrated fewer global switch costs in a task switching paradigm [101]. These findings indicate that the cognitive benefits of engaging in aerobic activities may be optimally extracted from specific forms of sports-playing that offer variable cognitive and physical demands. However, due to limited available literature, the exact perceptual and cognitive benefits of several types of open-skill sports in older adulthood can only be speculated at this time. As discussed, a number of perceptual-cognitive skills are assumed to support racket sports playing, which embody unique perceptual, cognitive, and motor constraints that may be especially beneficial for older adults. A large cohort study found all-cause mortality rates were $47 \%$ lower, and cardiovascular diseaserelated mortality was $56 \%$ lower in individuals who played racket sports, when compared with other types of physical activities that included swimming, aerobics, cycling, running and soccer [102]. Although limited in number, studies with tennis players have demonstrated task-relevant cognitive benefits in areas of eye-hand coordination and collision-detection [103,104]. One study found better performance on a test targeting attention and executive function in older adult table tennis players [105]. However, the promising results of some studies targeting sportsplaying older adults have been tempered by the use of only a limited number of unstandardized cognitive assessments. More importantly, a causal relationship has yet to be established between certain types of open-skill sports and improved perceptual and cognitive function in older adults within the existing research.

\section{Conclusions and Future Directions}

To recapitulate, the body of research that examines the cognitive

\section{References}

1 Laditka JN, Laditka SB, Liu R, Price AE, Wu B, et al. (2011) Older adults concerns about cognitive health: commonalities and differences among six United States ethnic groups. Ageing Soc 31: 1202-1228.

2 Bherer L, Kramer AF, Peterson MS, Colcombe S, Erickson K, et al. (2005) Training effects on dual-task performance: Are there agerelated differences in plasticity of attentional control? Psychol Aging 20: 695-709.

3 Plemons JK, Willis SL, Baltes PB (1978) Modifiability of Fluid Intelligence in Aging: A Short-Term Longitudinal Training Approach. J Gerontol 33: 224-231. impact of physical exercise is encouraging, although the evidence of the effects of specific sports activities in elderly adults has remained sparse. Nonetheless, there is a consensus within the literature that physical exercise/fitness has a protective effect on cognition, although there is a continued need for investigations that employ satisfactory blinding procedures, sufficient sample size, longer durations, and follow-up testing. A growing body of evidence has supported the causal influence of activity-dependent structural brain changes and concomitant improvement of cognitive functioning. Both animal and human models have suggested that voluntary fitness is associated with a more highly preserved and adaptive aging brain. Studies have shown improvement in a variety of cognitive areas following various fitness interventions in older adults, although only few have explored the effects of physical exercise on perceptual functions. Furthermore, many existing studies have been questioned in terms of their quality and inclusion of standardized neurocognitive assessments.

Despite the potential of physical exercise to enhance cognitive and neural health well into older adulthood, there are several remaining research questions which are currently amenable to speculation only. One of the most pertinent remaining questions within the available evidence concerns the exact effect that exercise type, duration, frequency, and intensity have on cognitive outcomes. The difference between various types of sports activities has barely been explored in terms of their cognitive training potential. Most sports activities involve a combination of complex locomotor sequences, manipulative skill, physical exertion, cognitive processes, and social interactions. Therefore, specific sports activities selectively involve disparate cognitive processing of activity-specific tactics and task constraints. However, some difficulty lies in parsing the network of perceptual, cognitive, and motor skills that underlie a certain sport activity, and the nature of the relationship between the performer and their environment. The literature would strongly benefit from studies that examine the protective or restorative effects that various types of sports activities may have on the cognition of older adults, as well as the extent to which engagement in different sports offers divergent performance gains in various areas of cognitive performance.

4 Verhaeghen P, Marcoen A, Goossens L (1992) Improving memory performance in the aged through mnemonic training: A metaanalytic study. Psychol Aging 7: 242-251.

5 Winocur G, Craik Fl, Levine B, Robertson IH, Binns MA, et al. (2007) Cognitive rehabilitation in the elderly: overview and future directions. J Int Neuropsychol Soc 13: 166-171.

6 Ball K, Berch DB, Helmers KF, Jobe JB, Leveck MD, et al. (2002). Effects of cognitive training interventions with older adults: $A$ randomized controlled trial. JAMA 288: 2271-2281.

7 Hultsch DF, Hertzog C, Small BJ, Dixon RA (1999) Use it or lose it: engaged lifestyle as a buffer of cognitive decline in aging? Psychol Aging 14: 245-263. 
8 Kramer AF, Bherer L, Colcombe SJ, Dong W, Greenough WT, et al. (2004). Environmental influences on cognitive and brain plasticity during aging. J Gerontol 59: M940-M957.

9 Drew B, Waters J (1986) Video games: Utilization of a novel strategy to improve perceptual motor skills and cognitive functioning in the non-institutionalized elderly. Cognitive Rehabil 4: 26-31.

10 Bugos JA, Perlstein WM, McCrae CS, Brophy TS, Bedenbaugh PH, et al. (2007) Individualized Piano Instruction enhances executive functioning and working memory in older adults. Aging Ment Health 11: 464-471.

11 Colcombe S, Kramer AF (2003) Fitness effects on the cognitive function of older adults: a meta-analytic study. Psychol Sci 14: 125-130.

12 Salthouse TA (1996) The processing-speed theory of adult age differences in cognition. Psychological Review 103: 403-428.

13 Luszcz MA, Bryan J (1999) Toward understanding age-related memory loss in late adulthood. J Gerontol 45: 2-9.

14 Rönnlund M, Nyberg L, Bäckman L, Nilsson LG (2005) Stability, growth, and decline in adult life span development of declarative memory: cross-sectional and longitudinal data from a populationbased study. Psychol Aging 20: 3.

15 Haaland KY, Price L, Larue A (2003) What does the WMS-III tell us about memory changes with normal aging? J Int Neuropsychol Soc 9: 89-96.

16 Troyer AK, Leach L, Strauss E (2006) Aging and response inhibition: Normative data for the Victoria Stroop Test. Aging Neuropsychol Cogn 13: 20-35

17 Wecker NS, Kramer JH, Hallam BJ, Delis DC (2005) Mental flexibility: age effects on switching. Neuropsychol 19: 345.

18 Denburg NL, Cole CA, Hernandez M, Yamada TH, Tranel D, et al. (2007) The orbitofrontal cortex, real-world decision making, and normal aging. Ann N Y Acad Sci 1121: 480-498.

19 Ball K, Owsley C (1993) The useful field of view test: a new technique for evaluating age-related declines in visual function. Optometry 64: 71-79.

20 Anderson ND, Craik FI, Naveh-Benjamin M (1998) The attentional demands of encoding and retrieval in younger and older adults: I. Evidence from divided attention costs. Psychol Aging 13: 405.

21 Mattay VS, Fera F, Tessitore A, Hariri AR, Berman KF, et al. (2006) Neurophysiological correlates of age-related changes in working memory capacity. Neurosci Lett 392: 32-37.

22 Reuter-Lorenz PA, Jonides J, Smith EE, Hartley A, Miller A, et al. (2000) Age differences in the frontal lateralization of verbal and spatial working memory revealed by PET. J Cogn Neurosci 12: 174-187.

23 Verhaeghen P, Steitz DW, Sliwinski MJ, Cerella J (2003) Aging and dual-task performance: a meta-analysis. Psychol Aging 18: 443-460.

24 Churchill JD, Stanis JJ, Press C, Kushelev M, Greenough WT, et al. (2003) Is procedural memory relatively spared from age effects? Neurobiol Aging 24: 883-892.

25 Singer T, Verhaeghen P, Ghisletta P, Lindenberger U, Baltes PB, et al. (2003) The fate of cognition in very old age: six-year longitudinal findings in the Berlin Aging Study (BASE). Psychol Aging 18: 318.

26 Raz N, Gunning-Dixon FM, Head D, Dupuis JH, Acker JD, et al. (1998) Neuroanatomical correlates of cognitive aging: evidence from structural magnetic resonance imaging. Neuropsychology 12: 95.
27 Raz N, Rodrigue KM, Head D, Kennedy KM, Acker JD (2004) Differential aging of the medial temporal lobe a study of a five-year change. Neurology 62: 433-438.

28 Salat DH, Kaye JA, Janowsky JS (1999) Prefrontal gray and white matter volumes in healthy aging and Alzheimer disease. Arch Neurol 56: $338-344$

29 Terry RD, Katzman R (2001) Life span and synapses: will there be a primary senile dementia? Neurobiol Aging 22: 347-348.

30 Visser PJ, Verhey F, Knol DL, Scheltens P, Wahlund LO, et al. (2009) Prevalence and prognostic value of CSF markers of Alzheimer's disease pathology in patients with subjective cognitive impairment or mild cognitive impairment in the DESCRIPA study: a prospective cohort study. Lancet Neurol 8: 619-627.

31 Striepens N, Scheef L, Wind A, Popp J, Spottke A, et al. (2010) Volume loss of the medial temporal lobe structures in subjective memory impairment. Dement Geriatr Cogn Dis 29: 75-81.

32 Perrotin A, Mormino EC, Madison CM, Hayenga AO, Jagust WJ (2012) Subjective cognition and amyloid deposition imaging: a Pittsburgh Compound B positron emission tomography study in normal elderly individuals. Arch Neurol 69: 223-229.

33 Heckemann RA, Keihaninejad S, Aljabar P, Gray KR, Nielsen CR, et al. (2011) Automatic morphometry in Alzheimer's disease and mild cognitive impairment. Neuroimage 56: 2024-2037.

34 Anstey KJ, Wood J (2011) Chronological age and age-related cognitive deficits are associated with an increase in multiple types of driving errors in late life. Neuropsychology 25: 613.

35 Wagner JT, Muri RM, Nef T, Mosimann UP (2011) Cognition and driving in older persons. Swiss Med Wkly 140: 13136.

36 Owsley C, Ball K, McGwin Jr G, Sloane ME, Roenker DL, et al. (1998) Visual processing impairment and risk of motor vehicle crash among older adults. JAMA 279: 1083-1088.

37 Braver ER, Trempel RE (2004) Are older drivers actually at higher risk of involvement in collisions resulting in deaths or non-fatal injuries among their passengers and other road users? Inj Prev 10: 27-32.

38 Baltes PB, Lindenberger U (1997) Emergence of a powerful connection between sensory and cognitive functions across the adult life span: a new window to the study of cognitive aging? Psychol Aging 12: 12

39 Lord SR, Clark RD, Webster IW (1991) Physiological factors associated with falls in an elderly population. J Am Geriatr Soc 39: 1194-1200.

40 Gittings NS, Fozard JL (1986) Age related changes in visual acuity. Exp Gerontol 21: 423-433.

41 Crassini B (1988) Age-related changes in contrast sensitivity in central and peripheral retina. Perception 17: 315-332.

42 Roudaia E, Bennett PJ, Sekuler AB, Pilz KS (2010). Spatiotemporal properties of apparent motion perception and aging. J Vis 10: 1-15.

43 Betts LR, Sekuler AB, Bennett PJ (2007) The effects of aging on orientation discrimination. Vis Res 47: 1769-1780.

44 Voleti VB, Hubschman JP (2013) Age-related eye disease. Maturitas 75: 29-33.

45 Blumenthal JA, Sherwood A, Babyak MA, Watkins LL, Waugh R, et al. (2005). Effects of exercise and stress management training on markers of cardiovascular risk in patients with ischemic heart disease: A randomized controlled trial. JAMA 293: 1626-1634.

46 Herriott MT, Colberg SR, Parson HK, Nunnold T, Vinik AI (2004) Effects 
of 8 weeks of flexibility and resistance training in older adults with type 2 diabetes. Diabetes Care 27: 2988-2989.

47 Blair SN, Nichaman MZ (2002) The public health problem of increasing prevalence rates of obesity and what should be done about it. Mayo Clin Proc 77: 109-113.

48 Minor MA, Hewett JE, Webel RR, Anderson SK, Kay DR (1989) Efficacy of physical conditioning exercise in patients with rheumatoid arthritis and osteoarthritis. Arthritis Rheumatol 32: 1396-1405.

49 Cooper C, Melton LJ (1992) Epidemiology of osteoporosis. Trends Endocrinol Metab 3: 224-229.

50 Flegal KM, Carroll MD, Kuczmarski RJ, Johnson CL (1997) Overweight and obesity in the United States: prevalence and trends, 1960-1994. Int J Obes 22: 39-47.

51 Kirkman MS, Briscoe VJ, Clark N, Florez H, Haas LB, et al. (2012) Diabetes in older adults. Diabetes Care 35: 2650-2664.

52 Strait JB, Lakatta EG (2012) Aging-associated cardiovascular changes and their relationship to heart failure. Heart Fail Clin 8: 143-164.

53 Taylor AH, Cable NT, Faulkner G, Hillsdon M, Narici M, et al. (2004) Physical activity and older adults: a review of health benefits and the effectiveness of interventions. J Sports Sci 22: 703-725.

54 Franco OH, de Laet C, Peeters A, Jonker J, Mackenbach J, et al. (2005) Effects of physical activity on life expectancy with cardiovascular disease. Arch Intern Med 165: 2355-2360.

55 Silverman MN, Deuster PA (2014) Biological mechanisms underlying the role of physical fitness in health and resilience. Interface Focus 4: 20140040.

56 Larson EB, Wang L, Bowen JD, McCormick WC, Teri L, et al. (2006) Exercise is associated with reduced risk for incident dementia among persons 65 years of age and older. Ann Intern Med 144: 73-81.

57 Yaffe K, Barnes D, Nevitt M, Lui LY, Covinsky K (2001) A prospective study of physical activity and cognitive decline in elderly women: women who walk. Arch Intern Med 161: 1703-1708.

58 Heyn P, Abreu BC, Ottenbacher KJ (2004) The effects of exercise training on elderly persons with cognitive impairment and dementia: a meta-analysis. Arch Phys Med Rehabil 85: 1694-1704.

59 Tomporowski PD (2003) Effects of acute bouts of exercise on cognition. Acta Psychol 112: 297-324.

60 Hillman CH, Snook EM, Jerome GJ (2003) Acute cardiovascular exercise and executive control function. Int J Psychophysiol 48: 307-314.

61 Kamijo K, Hayashi Y, Sakai T, Yahiro T, Tanaka K, et al. (2009) Acute effects of aerobic exercise on cognitive function in older adults. $J$ Gerontol B Psychol Sci Soc Sci 64: 356-363.

62 Hogan CL, Mata J, Carstensen LL (2013) Exercise holds immediate benefits for affect and cognition in younger and older adults. Psychol Aging 28: 587-594.

63 Molloy DW, Beerschoten DA, Borrie MJ, Crilly RG, Cape RDT (1988) Acute effects of exercise on neuropsychological function in elderly subjects. J Am Geriatr Soc 36: 29-33.

64 Dustman RE, Emmerson R, Shearer D (1994) Physical activity, age, and cognitive-neuropsychological function. J Aging Phys Act 2: 143-181.

65 Hillman CH, Erickson KI, Kramer AF (2008) Be smart, exercise your heart: exercise effects on brain and cognition. Nature Rev Neurosci 9: 58-65.

66 Barnes DE, Yaffe K, Satariano WA, Tager IB (2003) A longitudinal study of cardiorespiratory fitness and cognitive function in healthy older adults. J Am Geriatr Soc 51: 459-465.

67 Aichberger MC, Busch MA, Reischies FM, Ströhle A, Heinz A, et al. (2010) Effect of physical inactivity on cognitive performance after 2.5 years of follow-up: longitudinal results from the Survey of Health, Aging, and Retirement (SHARE). GeroPsych 23: 7-15.

68 Manini TM, Everhart JE, Patel KV, Schoeller DA, Cummings S, et al. (2009) Activity energy expenditure and mobility limitation in older adults: differential associations by sex. Am J Epidemiol 169: 1507-1516.

69 Marquis S, Moore MM, Howieson DB, Sexton G, Payami H, et al. (2002) Independent predictors of cognitive decline in healthy elderly persons. Arch Neurol 59: 601-606.

70 Muscari A, Giannoni C, Pierpaoli L, Berzigotti A, Maietta P, et al. (2010) Chronic endurance exercise training prevents aging-related cognitive decline in healthy older adults: a randomized controlled trial. Int J Geriatr Psychiatry 25: 1055-1064.

71 Smith PJ, Blumenthal JA, Hoffman BM, Cooper H, Strauman TA, et al. (2010) Aerobic exercise and neurocognitive performance: a metaanalytic review of randomized controlled trials. Psychosom Med 72: 239-252.

72 Kirk-Sanchez NJ, McGough EL (2014) Physical exercise and cognitive performance in the elderly: current perspectives. Clin Interv Aging 9: 51-62.

73 Liu-Ambrose T, Nagamatsu LS, Graf P, Beattie BL, Ashe MC, et al. (2010) Resistance training and executive functions: a 12-month randomized controlled trial. Arch Intern Med 170: 170-178.

74 Langlois F, Vu TTM, Chassé K, Dupuis G, Kergoat MJ, et al. (2013) Benefits of physical exercise training on cognition and quality of life in frail older adults. J Gerontol B Psychol Sci Soc 68: 400-404.

75 Lautenschlager NT, Cox KL, Flicker L, Foster JK, van Bockxmeer FM, et al. (2008) Effect of physical activity on cognitive function in older adults at risk for alzheimer disease: A randomized trial. JAMA 300 : 1027-1037.

76 Grodstein F (2007) Cardiovascular risk factors and cognitive function. Alzheimers Dement 3: S16-S22.

77 Sparks DL, Scheff SW, Liu H, Landers TM, Coyne CM, et al. (1995) Increased incidence of neurofibrillary tangles (NFT) in non-demented individuals with hypertension. J Neurol Sci 131: 162-169.

78 Thompson PD, Buchner D, Piña IL, Balady GJ, Williams MA, et al. (2003) Exercise and physical activity in the prevention and treatment of atherosclerotic cardiovascular disease a statement from the Council on Clinical Cardiology (Subcommittee on Exercise, Rehabilitation, and Prevention) and the Council on Nutrition, Physical Activity, and Metabolism (Subcommittee on Physical Activity). Circulation 107: 3109-3116.

79 O'Brien J, Erkinjuntti T, Reisberg B, Roman G, Sawada T, et al. (2003) Vascular cognitive impairment. Lancet Neurol 2: 89-98.

80 Intlekofer KA, Cotman CW (2013) Exercise counteracts declining hippocampal function in aging and Alzheimer's disease. Neurobiol Dis 57: $47-55$

81 Cotman CW, Berchtold NC (2007) Physical activity and the maintenance of cognition: learning from animal models. Alzheimers Dement 3: 30-37.

82 Molteni R, Zheng JQ, Ying Z, Gómez-Pinilla F, Twiss JL (2004) Voluntary exercise increases axonal regeneration from sensory neurons. Proc Natl Acad Sci USA 101: 8473-8478. 
83 Fordyce DE, Farrar RP (1991) Physical activity effects on hippocampal and parietal cortical cholinergic function and spatial learning in F344 rats. Behav Brain Res 43: 115-123.

84 Van Praag H, Christie BR, Sejnowski TJ, Gage FH (1999) Running enhances neurogenesis, learning, and long-term potentiation in mice. Proc Natl Acad Sci USA 96: 13427-13431.

85 Van Praag H, Shubert T, Zhao C, Gage FH (2005) Exercise enhances learning and hippocampal neurogenesis in aged mice. J Neurosci 25 8680-8685.

86 Heine VM, Maslam S, Joëls M, Lucassen PJ (2004) Prominent decline of newborn cell proliferation, differentiation, and apoptosis in the aging dentate gyrus, in absence of an age-related hypothalamuspituitary-adrenal axis activation. Neurobiol Aging 25: 361-375.

87 West MJ (1993) Regionally specific loss of neurons in the aging human hippocampus. Neurobiol Aging 14: 287-293.

88 Hu S, Ying Z, Gomez-Pinilla F, Frautschy SA (2009) Exercise can increase small heat shock proteins (SHSP) and pre-and post-synaptic proteins in the hippocampus. Brain Res 1249: 191-201.

89 Colcombe SJ, Erickson KI, Scalf PE, Kim JS, Prakash R, et al. (2006) Aerobic exercise training increases brain volume in aging humans. $J$ Gerontol A Biol Sci Med Sci 61: 1166-1170.

90 Colcombe SJ, Erickson KI, Raz N, Webb AG, Cohen NJ, et al. (2003) Aerobic fitness reduces brain tissue loss in aging humans. J Gerontol A Biol Sci Med Sci 58: 176-180.

91 Pereira AC, Huddleston DE, Brickman AM, Sosunov AA, Hen R, et al. (2007) An in vivo correlate of exercise-induced neurogenesis in the adult dentate gyrus. Proc Natl Acad Sci USA 104: 5638-5643.

92 Van der Borght K, Kóbor-Nyakas DÉ, Klauke K, Eggen BJL, Nyakas C, et al. (2009) Physical exercise leads to rapid adaptations in hippocampal vasculature: temporal dynamics and relationship to cell proliferation and neurogenesis. Hippocampus 19: 928-936.

93 Mather AS, Rodriguez C, Guthrie MF, McHarg AM, Reid IC, et al. (2002) Effects of exercise on depressive symptoms in older adults with poorly responsive depressive disorder: randomised controlled trial. Br J Psychiatry 180: 411-415.

94 Seynnes O, Fiatarone Singh MA, Hue O, Pras P, Legros P, et al. (2004)
Physiological and functional responses to low-moderate versus highintensity progressive resistance training in frail elders. J Gerontol A Biol Sci Med Sci 59: M503-M509.

95 Voss MW, Kramer AF, Basak C, Prakash RS, Roberts B (2010) Are expert athletes 'expert' in the cognitive laboratory? A meta-analytic review of cognition and sport expertise. Appl Cogn Psychol 24: 812-826.

96 Wang CH, Chang CC, Liang YM, Shih CM, Chiu WS, et al. (2013) Open vs. closed skill sports and the modulation of inhibitory control. PloS One 8: e55773.

97 Di Russo F, Bultrini A, Brunelli S, Delussu AS, Polidori L, et al. (2010) Benefits of sports participation for executive function in disabled athletes. J Neurotrauma 27: 2309-2319.

98 Williams AM, Ward P, Knowles JM, Smeeton NJ (2002) Anticipation skill in a real-world task: measurement, training, and transfer in tennis. J Exp Psychol Appl 8: 259-270.

99 Alain C, Proteau L (1980) Decision making in sport. In: Psychology of Motor Behavior and Sport (Nadeau CH, Halliwell W, Newell KM, Robert GC Eds). Champaign, IL: Human Kinematics, pp: 465-477.

100 Crognier L, Féry YA (2005) Effect of tactical initiative on predicting passing shots in tennis. Appl Cogn Psychol 19: 637-649.

101Dai CT, Chang YK, Huang CJ, Hung TM (2013) Exercise mode and executive function in older adults: an ERP study of task-switching. Brain Cogn 83: 153-162.

102 Kelly OP, Pedisic Z, Titze S, Bauman A, Foster C, et al. (2016) Associations of specific types of sports and exercise with all-cause and cardiovascular-disease mortality: a cohort study of 80306 British adults. Br J Sports Med 51: 812-817.

103 Lobjois R, Benguigui N, Bertsch J (2006) The effect of aging and tennis playing on coincidence-timing accuracy. J Aging Phys Act 14: 74-97.

104Lobjois R, Benguigui N, Bertsch J, Broderick MP (2008) Collision avoidance behavior as a function of aging and tennis playing. Exp Brain Res 184: 457-468.

105 Kawano MM, Mimura K, Kaneko M (1992) The effect of table tennis practice on mental ability evaluated by Kana-Pick-out test. Int J Table Tennis Sci 1: 57-62. 